\title{
A study on the evaluation and feedback of general computer composition for College English Teaching
}

\author{
ZHENG Weiwei ${ }^{1, \text { a }}$ \\ ${ }^{1}$ Jilin Business and Technology College, Changchun 130000,China \\ aemail: zhengweiwei@163.com
}

Keywords: English teaching; general computer; composition score

\begin{abstract}
In actual teaching, we found that the traditional liberal arts teaching, in composition, including English composition correcting prevailed two methods: one is the teacher with dazzling red pen "tick" and "X" marking, and finally a few perfunctory remarks slightly comment; another is the teacher often to student's thesis of surface group. For the former, almost everyone (including the teachers who are correcting) are considered to have very little effect, this simple but too extensive way apparently can not keep up with today's English teaching.
\end{abstract}

\section{Introduction}

Teacher's correction and feedback not only to give students a grade or score, but also to make a process of evaluation. Only by fully understanding the process of writing and feedback, students can always be in an active learning, the effect of feedback will be more rational and idealistic. Because the students' writing is a process, writing feedback is a continuation of the writing process, the students' writing ability is closely related to the feedback effect of the teachers. This shows that the effective correction and feedback of the role of self-evident. So, how to correct the composition of students to effectively correct and feedback it?[1]

This requires teachers to create a humanized feedback environment, taking into account the writing level of different students. So-called create a humane environment feedback is that teachers should stand in the position of the students, close to each student's interest, hobby and the personal skills and aptitude "rating." This can not only ease the pressure on students, but also stimulate students' interest in writing. Therefore, for writing on the basis of good students in addition to must also give improvements; for writing the basis of poor students, take the combination of encouragement and guidance -- use encouraging language establish their self-confidence, and to discuss the tone shall refer to the guide.

Students just to write a good composition on the subject of understanding, conception, structure, word sentences were still fresh in my memory, at this time if the teacher strike while the iron is hot, classroom to guide students to marking can produce good correcting effect. Such as: "how toBuild a harmonious society?" as an example, according to the understanding of students, and formulate the following classroom correction scheme. Choose good, poor, a composition (unsigned and advance don't tell students the composition level), through the projection classroom projection to the students in the class to read, which is then displayed on a computer monitor to provide a standard evaluation: the author's point of view is clear[2]; paragraphs are the service from the point of view; between paragraphs and sections and the connection is reasonable and smooth; if the end did tail echo or deepen the theme, or put forward suggestions to solve the problem. Then let the student control standards, evaluation of these three articles. The purpose is to let the students understand the composition score from the content (ideas and materials), language and structure of the three aspects. Then ask the students to make the overall feedback to the three compositions. Students' feedback may be quite different from the actual situation, but the teacher may be able to make a specific analysis of this point. Then, further analysis of the teachers' demonstration, were pointed out the advantages and disadvantages of the three articles in the classroom exercises. In this way, students of different levels have a reference, have the development of space, but also easy for students to have a more in-depth understanding of their composition. 


\section{General method of teacher's correcting composition}

The traditional approach is to correct the mistakes in the composition of the students with red pencil, and then give the score. The red pen marking the content is the wrong content. As everyone knows, the student's psychology is afraid of red, and even resist the red. In this way, why don't you think about it, try to communicate with students, and use some methods to correct the students' approval. Some teachers in correcting the students' composition, try using green fluorescent strokes out student writing good word good sentence, with purple painted a student in tense and collocation errors. Purple often focus on correcting sentence level errors, error correction and easier for students to strengthen memory. Practice shows that the modified with except the red marker, not on students caused visual impact, can alleviate red over "warning" blow on the students' self-confidence. Therefore, the color correction method not only does not hurt the student's self-esteem, but also to enable teachers and students to get rid of the aesthetic fatigue. This correcting method can also be used in the student's mutual correction[3].

According to the study, teacher's corrections have quite a part belongs to the "chicken ribs". Because of these so-called "wrong" is just and teacher's style is not identical. So "unpalatable" "chicken ribs" not only can improve the students writing level, and may change as a result of the students want to express meaning. The appearance of sign correcting, which not only reduces the burden of teachers, but also provides students with thinking. Students from accepting the teacher's point of view has become the initiative to explore the study, so that students really become the beneficiaries of writing.

For example, "said unnecessary words;"? "Said don't understand students in expressions." / / "said here needs a separate section;"!! "said students here made should not make the mistake." [] "says this section must be rearranged; so is the wife said this part is not quite right and need more clear expression.

Teachers use symbols to mark the type of students' mistakes, help students identify errors, self correction, so as to achieve the purpose of the students' Autonomous learning. The symbol marking the effective implementation of the need between teachers and students for symbols were running for a period of time and adaptation, and in correcting, and there is no need to mark students make all the mistakes, but should be according to the students' English level focus.

Dialogue between teachers and students has a strong pertinence, because each student's mistakes are not the same. This way can be read in class, also can be in after class; can be finished at the same time, also can be done multiple times. From the feedback effect, the dialogue between the teachers and students have great room for communication, teachers can provide students with guidance from the language knowledge, content, and even the style of the appropriate and orderly development and so on.

In the past the focus of attention of students in addition to the composition of the score is the teacher's language error correction. So, when the students just contact with the problem may be quite not adapt. But only by forcing the students to reflect on their writing purpose, their writing can be a qualitative leap. After all, the purpose of writing is the first meaning of writing. Therefore, in the implementation of the method also need a run in period to correct the students in the past to form the wrong idea. For this problem, if the student's first draft is not clear, then, this step will have to continue until second, or even third draft, until they can give a clear answer.

Once students have a clear purpose and meet the purpose of the content, teachers can the emphasis placed on the organization structure, to explore the rhetoric, logic, the paragraphs in the integrity and paragraphs argument, effective opening and effective at the end of problems. The author thinks that the language expression is very important. To make the language clear, clear, and vivid, easy and lively thing is not done overnight. This is the formation of the personal style of writing, and this is no doubt a gradual process of gradual accumulation. In this process, the effective correction and guidance of teachers will play a very big role in promoting. Therefore, the content of the correction is the most important. In correcting finally, to allow for comparison of the transposition between students and between teachers and students, let the students to appreciate and understand the expression of the "gifted pen". 
In the experience of the "content" such a top-down process, teachers can shift to more microscopic sentences -- on the sentence level look for grammatical mistakes, but not exhaustive. If the article has a lot of subject verb disagreement, they can focus on this topic, and then analyze grammatical errors, and require students to correct the all similar mistakes.

The above three issues is a top-down, from the overall to the local correction process. In this process, the teacher can also use the silent way, let the students talk about the article, the teacher only gives some affirmation or advice. In this way, the integrity of the work of students can be maintained, but also to enhance their self-confidence[4].

Through the way of dialogue between teachers and students, students can truly understand their own problems in writing, and get the specific guidance of teachers. Moreover, the professionalism of teachers to enable the students to move, they naturally will produce a "to write bad feeling of microscopic composition of his elders. This marking effect is completely reflected.

Because the school can in detail with student dialogue time limited, and general marking and difficult to achieve the ideal effect, teachers can try to use the telephone or the Internet, give students more effective recommendations.

\section{The ability to solve problems by using the method of correcting students}

(1) correcting each other

After the students complete the first draft of the group. Generally speaking, there are two kinds of grouping methods, one is to divide the students into a group, which will help the two sides to improve. Another is the teacher marking the first level students composition, correcting composition of the second level, the first level of students, followed by analogy. I prefer to the latter, because such teachers can not physical overdraft has more energy "batch", and students in this process can "to people as a mirror," according to many of their own not been aware of the problem.

In this process, in order to ensure that all students are able to seriously modify the composition of others, teachers should closely observe the progress of each student, to understand their difficulties and needs, to provide the necessary guidance and help. Once the students accepted this approach, at the time of writing will not consciously put companion are also presented for the readers and make the students' writing more in line with their age, psychology, interest and other characteristics of the times, the more authentic and readable. Finally, the arrangement is a collective discussion, requiring students to list some of the typical errors, of course, they can also put forward different views. This approach has produced multiple levels of interaction, providing a wealth of information for each student and the right feedback.

It is worth mentioning that the marking patterns do not often. On the one hand, the ability of students is limited, marking the quality will not achieve the desired effect. On the other hand, often such marking, to enable students to start writing, lack of will power, because even if write again good, the teacher also don't know. There are students, too lazy to think from a higher level, to feel, so, this approach can only be.

(2) self correcting

Self correcting refers to the students to hand in the first version of the composition (the first version of the teacher will not be corrected), the teacher on some attention and possible problems for public guidance, and then the first draft was issued to the students. Students on the basis of the guidance of teachers, the first draft of their evaluation (you can ask them to write a paragraph of self evaluation in English) and to modify. After such two steps, the students to hand in the final draft, the teacher to correct the final draft and simple feedback. In this process, the students act as the protagonist of the correction. Self correcting can encourage students to "technical support" on the basis of teachers to find problems and to be corrected. Students only in the real understanding of their strengths and weaknesses, in order to clear the way of thinking, to improve themselves, to seek greater progress. Generally speaking, the method of correcting students reflects the process of students' active learning. In this process, students learn to the students and teachers to learn, learn how to face the problem, develop the ability to solve problems, will greatly promote the improvement of English learning initiative. 


\section{Make use of the advantages of network resources to modify}

The popularity of the network, between teachers and students can overcome space hinder effective communication, especially during the holidays, the teacher can through e-mail or QQ group and other ways to guide the campus students, students can also through the correction of yourself and your classmates to improve their work. Through the WORD's "review" toolbar, teachers and other students can easily insert comments, exchange their ideas. And the color of these annotations can be set arbitrarily, also can be saved into a different versions to record the correcting process (through the page views can be to observe the whole process of correcting), ease of self-evaluation, peer evaluation and reflection. Network to correct the application, not only can get rid of the shackles of time and space, but also achieved good results.

There is also a way to add sound. Just by changing the text in the print version of the appearance, you can easily add sound to the document. Word can easily be around the text around the irregular objects (such as sound objects) around, including the object of the optional graphics (which can be found on the Drawing toolbar), etc.. This allows students to give full play to their imagination to creative writing tasks, but also makes the content more cordial, more able to arouse the interest of students, improve the effectiveness of the composition of the correction. At the same time, students in the process of writing also mastered the use of computer skills[5].

In addition, by using the "revised" tool in Word software, you can clearly indicate the amendments to the article. Moreover, through the electronic text writing and e-mail correcting to improve efficiency.

The network marking the completion of after, teachers can require each student submitted a final draft, scoring, then all the students composition aggregated into an electronic document by e-mail sent to each and every one of my classmates, play each other the effect.

At present, many schools have installed multimedia classrooms, some schools also opened the Internet, but also the computer room at noon to the students. With the support of these hardware conditions, teachers can carry out the network to correct, complete the effective feedback on the composition of students.

Two 4 evaluation methods are combined to actively use the language of motivating students

Teachers in marking students' writing process should be done not to let the students have the "grammar is important to writing" such a kind of illusion. That is to say, teachers are not in the marking process only on surface error feedback, not wrong to an article as a series of independent sentence view, so that they ignore the integrity and logicality. It is necessary for teachers to comment on the structure, content, language and so on. Generally speaking, the overall comments appear at the end of the composition, and comments in the process of correction are often made by teachers for a specific problem.

The following steps can be used as reference:

First of all, teachers are needed in the paper at least read feedback. In the process of reading, with the green pen will be good words to draw a good sentence.

Secondly, read it again, this time to pay special attention to the structure and content of the article, considering the overall evaluation is given in the end what.

Again, to carry out the overall feedback. Note that this feedback should be comprehensive, but there is a choice. To highlight the key, instead of pointing out all the problems of students, if blindly pointed out that the deficiencies of the students, let them feel that their problems too, and their writing ability of doubt, so that the loss of confidence. On the contrary, before pointing out the existing problems, the teacher should first praise the progress made by the students, and then put forward some constructive and operable suggestions. Write reviews, and questions will than imperative sentences can reflect the respect of teachers to students, and does not have too big to kill.

Finally, in the process of reading the third times, the teacher in the text for the details of comments, usually this kind of interspersed in the article comments on the overall evaluation of the overall evaluation of the article.

Example: "in general, your language is very fluent and do youexpress your ideas quite well. However, you might as well payattention to use your of tenses and voices." obviously, this 
evaluation in affirming the advantages and bring out the shortcomings is a holistic, incentive and easily accepted by the student evaluation.

Three, reflection

In fact, no matter what kind of way, have their pros and cons. Classroom correcting with high efficiency, can produce immediate results; however, only examines three compositions, the sphere of influence is far from enough. Color correcting and symbol marking are foreign advanced marking concept, however, would cause cultural "acclimatized" in practice remains to be the test of. Students have already had the way, but there is no case shows that this approach will improve the students' writing level.

\section{Conclusion}

Dialogue between teachers and students is the most effective way, but it challenges the professionalism of teachers and teachers' morality. On the other hand, it also puts forward higher requirements on the level of writing. At the same time, to rational allocation of teacher preparation, marking the operation, business and learning time and composition of grading and feedback time, teachers can only be in to ensure the high-efficiency other before they can out a time for the dialogue between teachers and students, and never in much sacrifice teachers of the time as the price.

\section{References}

[1] Gao liming, modern education technology [M]. Beijing: The Open University of China press, 1997.

[2] Hu Jiyue, Zhang Guoying, Shen Lanping, research on the teaching mode of the development of English network curriculum [J], foreign telephone teaching, 2003, 1, 12-15.

[3] Kong Wen, Li Qinghua, the concept of language teaching and Computer Assisted Language Teaching [J] foreign language telephone teaching, 2002, 2, 34-35.

[4] Zhuang Wei, Wu Min, Huang Wei, National College "new concept" College English network teaching pilot program [M]. Shanghai foreign language education press, 2004, 9.

[5] Zhang Hua, modern educational technology and foreign language teaching mode [J] foreign language telephone teaching, 2002, 1,48-50. 